\title{
A proposed Program from Perspective of Social Group Work Method and developing University Youth Groups' Awareness of Entrepreneurial Skills
}

Mohamed M. Soliman Mahmoud

Assistance Professor of Social Group Work

Social Work Faculty - Assiut University 
مجلة كلية الخدمة الاجتماعية للار اسات و البحوث الاجتماعية - جامعة الفيوم 


\section{Abstract:}

This study aims to design a proposed program in terms of group work to boost the awareness of university youth groups about entrepreneurial skills. Given this, the analytical descriptive and the general social survey methodologies were put into effect to a population of (207) male and female university youths, to whom an online questionnaire was applied. Put into practice, the study reached some results, the most significant of which are: the potential to compete and create innovative marketing ideas of the project, and the potential to make appropriate decisions that are commensurate with projects with positive goals. Among the most important entrepreneurial skills for university youth groups are, respectively, entrepreneurship technical skills for university youth groups, business management skills, besides entrepreneurship personal skills for university youth groups. Pertaining to the barriers which hinder promoting university youth groups' awareness of entrepreneurial skills, the study stresses the lack of training programs meant for youths on entrepreneurship, the deficiency of societal awareness of entrepreneurship value, the complexity of laws and procedures that regulate starting a private business, and the insufficiency of funds essential to implement enterprises.

Key Words: Program, Group Work Method, Awareness, Skill, Entrepreneurship.

$$
\begin{aligned}
& \text { برناهم هقترح هن هنظور طريقة العمل هع الجماعات وتنمية وعي جماعات الشباب الجاهعي } \\
& \text { بمهارات ريادة الأعمال } \\
& \text { الملخص }
\end{aligned}
$$




\section{Study Problem:}

Given a human being is a key element of life, all the world countries seek to bring about comprehensive development and exert efforts to care for her and achieve her well-being with respect to all life areas.

Accordingly, development is meant to pay attention to the human element in terms of values, behaviors and attitudes. It is also concerned with preparing an individual as a human being concerning education, training, and skills that make her a positive and helpful element in bringing about the development process in society. (Gordian, 2020,45)

Internationally, the successive developments in the political, economic and social settings, as a result of information and communication technology breakthrough, have led to the introduction of new concepts regarding the role that individuals and groups can play in human and societal development. (Crawshaw \& Budhwar, 2021, 76 )

Nonetheless, this rapid advance in technology in addition to the surge in human and scientific knowledge, has resulted in the absence of a proper balance between modern technology and social life. Thus, for an individual's inability to cope with this huge flow in technological means and rapid developments, several modern trends has come into existence. (Sowers, 2015, 112)

Various professions have been interested in studying these modern trends, including entrepreneurship and its role in sustainable development process. Further, they have initiated many practices, plans, procedures and educational programs relevant to promoting entrepreneurship culture, supporting entrepreneurs, creating an adequate environment to set up their own businesses, fostering the fulfillment of their goals, in addition to providing all the circumstances which guarantee the survival of such businesses (Terry, 2017, 69). Smarten confirmed this point emphasizing the significance of entrepreneurship as a primary factor in reinforcing economic development, innovation, competitiveness and creation of various job opportunities for youth (Smarten, 2018).

Social work profession today is utilized in a variety of settings and agencies. Some of the important ones are psychiatric, medical, the school, rehabilitation, public welfare, workplace, youth. Settings of social work train a student to work in any agency, giving him or her generic understandings, skills, and attitudes that make it possible to function adequately.(CSWE, 2015)

Social work practice consists of the professional application of social work values, principles, and techniques to one or more of the following ends: helping people obtain tangible services; counseling and psychotherapy with individuals, families, and groups; helping communities or groups provide or improve social and health services; and participating in legislative processes. The practice of social work requires knowledge of human development and behavior, of social and economic, and cultural institutions; and of the interaction of all these factors. (NASW, 2010).

Social work is based on three premises: (1) that the person is important; (2) that he or she has personal, family, and community problems resulting from interaction with others; and (3) that something can be done to alleviate these problems and enrich the individual's life. (Healy, Thomas, 2020, 34)

And, social work is the professional activity which aims to help individuals, groups, and communities enhance and change their capacity for social functioning and to help create social conditions that promote beneficial change in the community (NASW, 2009). 
Group work is a method of social work practice through which individuals are helped in solving their problems and it is also directed towards bringing about desired changes at the individual, group and community levels. The group work method is functional at two levels the individual and the entire group. (Black, 2016, 87)

Social group work helps individuals to develop their inherent potential and identify their innate abilities to cope better with their environment. It helps them to learn and inculcate new patterns of behavior, which in no way are limited to their place within the group but need to be sustained beyond their participation in their life. Thus group work provides emotional and social support to its members; encourages democratic participation and citizenship; assists them in learning and performing new roles and remedies their maladjustments. (Lindsay, \& Orton, 2016, 25)

And, purpose of group work is to help improve the well-being of the members and relieve personal suffering. This is accomplished because groups have the "power to enhance problemsolving capacity, prevent the development of serious social problems, and restore and maintain the social functioning of members'. Group work is used in all settings of social work.(Garvin, \& Galinsky, 2017, 121)

In order to achieve its goals, a method should use changing tools, the most important of which is the program, as it is a group's means of directing experience and psychological attitudes that members acquire human life fields with the assistance of a social worker.(Ahmed, 2000) This sense was confirmed by a study that indicated that group work programs have a role in influencing group members concerning providing them with plenty of knowledge, experience and skills that help them adapt in society. More, another study assumed that a group work program is a key tool that group workers may utilize to help members with physical, social, psychological and mental aspects. Additionally, it provides opportunities for members to learn and practice the cognate and integrated social roles that targets at attaining group goals. (Abed, 1998)

This method deals with various groups, including the youth one, which is supposed to be one of the fundamental resources for achieving the goals of economic and social development in society.) (Zastrow, 2004, 82) Besides, it is argued that the method can be looked upon as a tool for accomplishing development and a main source to build up any society. In other words, developing youth means boosting the sustainability of society and ensuring its well-deserved human dignity through empowering diverse groups and achieving social and economic development.

Nab'a's study (2011) emphasized the necessity to utilize young people's energies and knowledge and build their scientific and intellectual capabilities in various settings of medical, engineering, social and cultural life.

Moreover, the method seeks to empower young people in miscellaneous areas since it can meet the goals for which they wish to join various groups. Among these is entrepreneurship, which is called to be a mechanism for change, development or strategic renewal, and is considered one of the inputs to the decision-making process pertaining to the use of the best available resources to gain access to the product or new service. Hence, entrepreneurship can be seen as a requisite, for it is an option that organizations may adopt to adjust to competition and change requirements. (Richard, 2007, 112)

Entrepreneurship is 'an individual's ability to turn ideas into action. It includes creativity, innovation and risk-taking, as well as the ability to plan and manage projects in order to achieve objectives'. It is seen as vital to promoting innovation, competitiveness and economic growth. Fostering entrepreneurial spirit supports the creation of new firms and business growth. However, entrepreneurship skills also provide benefits regardless of whether a person sees their future as starting a business. They can be used across people's personal and working lives. as they 
encompass 'creativity, initiative, tenacity, teamwork, understanding of risk, and a sense of responsibility' (European Commission ,2013)

In addition to knowledge, an opportunity should be given to young people for developing new skills and competences. These skills should be developed in a person from childhood by implementing various entrepreneurship education programs at all levels of education, and through lifelong learning.

Regni study (2010) concurred with this view stressing the significance of entrepreneurship in providing many job opportunities for young people given the incompetence of community institutions to meet their demands.

Al-Saeed study (2018) highlighted the role of entrepreneurship with university youth in providing many ideas that help them introduce distinct creative enterprises (Sultan, 2018)

Entrepreneurship is considered to be a key factor in promoting economic development, innovation, competitiveness and job creation, yet little is known about the skills required for successful entrepreneurship.( Germane, 2016)

Skills for successful entrepreneurship The literature review supports many of the existing ideas regarding which skills are important for successful entrepreneurship including, $\bullet$ identifying customer needs, technical opportunities and market opportunities, as summarized by Hayton (2015) - creation of new opportunities (Alvarez \& Barney, 2007) - recognizing social/market needs (Hunter, 2012) • successful entrepreneurs may find (or create) an opportunity and then develop skills to capitalize on the opportunity.

Skills development prevails as a research issue in higher education dominion; it is the primary goal to be achieved by the students (Lackéus 2015; Roy and Das 2016; Zeng and Honig 2016). Skills development is perceived as a strategic management tool to cope with the current business environment (Nyhan 1998), mainly because of the market that has changed from one of mass production to one of customization, whereby quality, price, and speed of delivery are stressed. This change has brought about new circumstances in which many organizations struggle to cope with new and emerging customer segments, cultural diversity in a global marketplace, market volatility, raised customer expectations about the quality of products and services, and the impact of the internet on an organization's core business. In the job market, there has been a growth in the higher-level jobs such as managerial and professional positions that require flexibility and problem-solving skills.

Based on the above conceptual framework, it becomes clear the importance of entrepreneurship skills and the need for imparting them to young people who function as the locomotive engine for social and economic development. Yet, addressing officials of the University's Entrepreneurship Center through semi-standardized interviews, a significantly poor awareness among university youth groups affiliated with the Entrepreneurship Center and the University's Business Incubator Center was apparently found. Proportionally, with the aim of increasing the awareness of entrepreneurial skills, the researcher contemplated the possibility of designing the program in hand. Given this, the study problem can be formulated in the following question: To what extent can the proposed program in terms of the perspective of group work contribute to developing the awareness of university youth groups of entrepreneurship skills?

\section{Study Importance:}

1- Young people are a principal human resource that contributes to the building and advancement of any society, for the substantial differences they make in its development. 
2- The state's interest in the university youth category for being the society's mainstays in the present and prospective leaders in the future in all fields, which requires all professions to collaborate to take care of them.

3- Social work is a humanitarian profession that pursues the attainment of various therapeutic, preventive and development goals through applying its methods to promote the university youth's awareness of entrepreneurial skills.

4- The efficacy of group work for having development and constructivist roles, and their reliance on several models and tools that would bring about change in society.

5- A group work-based program functions as a tool for developing the social performance of group members and imparting them with a wide range of concepts, knowledge, experience and skills related to entrepreneurship skills.

6- The concept of entrepreneurship skills is receiving growing attention worldwide due to the crucial role entrepreneurship plays in keeping pace with economic and social developments.

7- The scarcity of majored research (whether in social work in general or group work in particular) on developing university youth's awareness of entrepreneurial skills,.

\section{Study Aims:}

1. Defining the concept of entrepreneurship for university youth groups.

2. Determining the types of entrepreneurial skills for university youth groups.

3. Determining the obstacles hindering the development of university youth groups' awareness of entrepreneurial skills.

4. Proposing a program based on the perspective of group work to develop the awareness of university youth groups about entrepreneurship skills.

\section{Study Questions:}

1. What is the concept of entrepreneurship skills for university youth groups?

2. What are the types of entrepreneurship skills for university youth groups?

3. What are the obstacles hindering the development of university youth groups' awareness of entrepreneurship skills?

4. What is the proposed program based on the perspective of group work to develop the awareness of university youth groups about entrepreneurship skills?

\section{Study Concepts:}

\section{1- A Program in Group Work Method:}

According to group work, a program is "every activity that a group undertake, whether inside or outside an institution; it is the primary tool that group workers and members use to develop and achieve desired social goals" (Ahmad, 2012, 122).

It is also defined as 'the concept or abstract idea that comprises both members' and groups' various activities, relationships, interactions and experiences, planned and conducted by the group itself and with the help of workers to meet their needs and satisfy their desires" (Fahmy, 2002, 251).

Similarly, it is denoted as "a set of multiple activities through which different group needs are regularly satisfied" (Jody, 2004, 54).

\section{Operationally, a program in group work can be defined as:}

- A set of activities undertaken by university youth.

- The activities are geared towards developing their entrepreneurial skills. 
- The activities are implemented within the limits of the available institutional and environmental capabilities, and during specific time periods.

- These activities will only be practiced with the aid and guidance of a social worker.

\section{2- Awareness Concept:}

Linguistically, the term 'awareness' indicates understanding and management safety; it is a mental characteristic that enables an individual to perceive both him/herself and the environment with dissimilar degrees of clarity and complexity. (Madkor, 1985)

Likewise, it is defined as a subjective cognitive perception of surrounding social conditions. (William, 2009, 157 )

In another definition, it is the sum of the thoughts and knowledge that run through one's mind and influence his/her decisions. (Grant \& John, 2013,247)

\section{In the context of the study in hand, awareness is operationally defined as:}

A- University youth's realization of the various types of entrepreneurship skills.

B- University youth's perception of the knowledge and requirements essential to the labor market.

C- University youth's recognition of the importance of entrepreneurial skills in chasing a project success.

\section{3- Entrepreneurial skills Concept:}

Entrepreneurship is the ability and readiness to develop, organize and run a business enterprise, along with any of its uncertainties in order to make a profit. The most prominent example of entrepreneurship is the starting of new businesses. (Onuoha,2007, 20-32)

And, refers to the process of creating a new enterprise and bearing any of its risks, with the view of making the profit.(GEM, 2016, 76)

Entrepreneurship is the process of doing something new and something different for the purpose of creating wealth for the individual and adding value to society. (Berzin, 2012, 22-32)

"Skill" is defined as measurable proficiency in the use of one's hands, knowledge, resources, talents, and personality. Skills include organizational skills, professional skills, administrative skills, disseminating information about available community resources, communication skills, problem-solving skills, intervention skills, emergency crisis intervention skills, research skills, technology skills, and teaching skills. (Cooney, 2012)

Entrepreneurial skills can encompass a broad range of various skill sets like technical skills, leadership and business management skills and creative thinking.

\section{Entrepreneurial skills can be operationally defined as:}

The competence of university youth to manage multi-purpose projects, starting from planning and implementation to evaluation in order that strengths and weaknesses can be identified. In this respect, they are committed to a set of technical, business management and personal skills.

\section{Theoretical Structure of the Study:}

Social work engages people and communities to address life challenges and traumatic events, to create change, and build resiliency. Social work also collaborates with other professionals, communities, and organizations to provide services, improve conditions, and create opportunities for growth, recovery, and personal development. 
Social group work aimed at helping individuals to enhance their functioning as social beings through face-to-face interactions in small groups. Members of the group seek either to change their own behavior, the behavior of other people, or both. The social worker in the group facilitates the way members pursue these goals by interacting with individuals in the context of the group, with the whole group, and with the people outside of the group on behalf of the group and its members (Furman, \& Bender, 2015, 91)

Being a social work method, group work handles youth groups to try to provide them with the experience and skills necessary to fulfill adjustment and interaction with their society. This can be done through its technical and practical techniques that may help achieve their goals and enable them contribute to the development of their society. In this way, they can positively contribute to enriching the life of the society as well. (Ahmed, 2011, 83) Therefore, group work assumes that it is possible to support members, develop their personalities and modify their attitudes by means of their relationships, interactions and experience with others in different groups of the same institution, which achieves its goals with the help of group workers. (Ahmed, 2002, 67)

Worth mentioning, establishing the culture of entrepreneurial skills in the society is a task that should be undertaken by all professions; it is a paramount necessity for economic development. Unarguably, developing such a culture would enable societies to better take control and provide them with entrepreneurial spirit due to technological advance, the introduction of globalization and privatization which have a great impact on the business environment, apart from competitiveness among local and international organizations. Thus, the interest in the concept of entrepreneurship stems from the role it plays in the growth of countries' economies at the macro level and the expansion of organizations and their access to financial and physical resources. (Michael \& Terry, 2001, 59)

And, it's dealing with entrepreneurship through using entrepreneurial methods to generate profits for an organization; entrepreneurship uses these profits to address some of the major social problems of our time. Entrepreneurship is concerned with generating profits but is ultimately driven to change the social issues of our time.( Thomas, 2017)

\section{(1) Characteristics of Entrepreneurship:}

Not all entrepreneurs are successful; there are definite characteristics that make entrepreneurship successful. A few of them are mentioned below: (Davidsson, 2008, 61)

- Ability to take a risk: Starting any new venture involves a considerable amount of failure risk. Therefore, an entrepreneur needs to be courageous and able to evaluate and take risks, which is an essential part of being an entrepreneur.

- Innovation- It should be highly innovative to generate new ideas, start a company and earn profits out of it. Change can be the launching of a new product that is new to the market or a process that does the same thing but in a more efficient and economical way.

- Visionary and Leadership quality: To be successful, the entrepreneur should have a clear vision of his new venture. However, to turn the idea into reality, a lot of resources and employees are required. Here, leadership quality is paramount because leaders impart and guide their employees towards the right path of success.

- Open-Minded: every circumstance can be an opportunity and used for the benefit of a company.

- Flexible: An entrepreneur should be flexible and open to change according to the situation. To be on the top, a businessperson should be equipped to embrace change in a product and service, as and when needed. 
- Know your Product: A company owner should know the product offerings and also be aware of the latest trend in the market. It is essential to know if the available product or service meets the demands of the current market, or whether it is time to tweak it a little. Being able to be accountable and then alter as needed is a vital part of entrepreneurship. (Chang, \& Rieple, 2013,225-241)

(2) Importance of Entrepreneurship: ( Jayeoba, 2012, 74-83)

- Creation of Employment- Entrepreneurship generates employment. It provides an entrylevel job, required for gaining experience and training for unskilled workers.

- Innovation- It is the hub of innovation that provides new product ventures, market, technology and quality of goods, etc., and increase the standard of living of people.

- Impact on Society and Community Development- A society becomes greater if the employment base is large and diversified. It brings about changes in society and promotes facilities like higher expenditure on education, better sanitation, fewer slums, a higher level of homeownership.

- Increase Standard of Living- Entrepreneurship helps to improve the standard of living of a person by increasing the income. The standard of living means, increase in the consumption of various goods and services by a household for a particular period.

- Supports research and development- New products and services need to be researched and tested before launching in the market. Therefore, an entrepreneur also dispenses finance for research and development with research institutions and universities. This promotes research, general construction, and development in the economy.

(3) Types of Entrepreneurship: ( Sharpley, 2012, 117)

It is classified into the following types:

\section{A) Small Business Entrepreneurship-}

These businesses are a hairdresser, grocery store, travel agent, consultant, carpenter, plumber, electrician, etc.

\section{B) Scalable Startup Entrepreneurship-}

This start-up entrepreneur starts a business knowing that their vision can change the world. They attract investors who think and encourage people who think out of the box.

\section{C) Large Company Entrepreneurship-}

These huge companies have defined life-cycle. Most of these companies grow and sustain by offering new and innovative products that revolve around their main products. The change in technology, customer preferences, new competition, etc.,

\section{D) Social Entrepreneurship:}

This type of entrepreneurship focuses on producing product and services that resolve social needs and problems. Their only motto and goal is to work for society and not make any profits.

(4) Entrepreneurial Strategies: include making decisions and taking responsibility for their consequences. Among the most important entrepreneurial strategies are:

1. Innovation: an action initiated by an individual to show his/her potential to come up with creative ideas. The change then occurs through the process in which an individual becomes sensitive to the problems he/she faces and the changes arising in the surroundings. Here, the concept of innovation can be conceived in terms of two notions: developing the 
creative idea, and the manner of implementing and transforming it into something beneficial .(Roddic, 2007).

2. Risk: implies that an entrepreneur jeopardizes launching new products regardless of competition hazards in markets. Indeed, risk is characterized by the following:

- Entrepreneurship variation is part of taking risk. In fact, entrepreneurs, more than others, tend to study the situation before risking, and their taken decisions may be more accurate than those of managers engaging in large organizations.

- Entrepreneurship tendency to possess and run businesses with a low degree of risk; i.e., a calculated risk in which the probability of success is greater than that of failure. (Simon, 2008)

3. Uniqueness: means introducing new techniques or creating new devices that contribute to presenting a product in a distinctive and sophisticated way.

4. Proactiveness: implies participation in future problems, needs and changes. It also means the extent to which new products and services, which are based on advanced technology and involve a high degree of risk, are introduced. (Andre, 2008).

(5) Entrepreneurship Skills:

Entrepreneurial skills can encompass a large range of both soft and hard skills. Because of the many business roles entrepreneurs may take on, they may also develop a variety of different skill sets to accommodate the growth of their businesses and brands. Developing the following skill sets can also help you develop your entrepreneurial skills. (Hessels, \& Grilo, 2011, 449)

- Teamwork and leadership skills

- Analytical and problem-solving skills

- Critical thinking skills

- Strategic thinking and planning skills

- Technical skills

- Branding, marketing and networking skills.

According to Nick and Leach (2010) and Roselina (2009), entrepreneurial skills can enhance the ability of entrepreneurs by encouraging them to take risks, identify the practical methods of business and prepare them to make all the opportunities available.

1. Technical Skills: Oral Communication, ability to organize, productive ability, technical business management, coaching, network building, monitoring environment, ability to spot new trends, active listening, writing and interpersonal skills.

2. Business Management Skills: Forecasting, planning, budgeting, decision making, negotiation, goal setting, human relations, marketing, finance.

3. Personal Skills: Ability to manage change, leadership, persistence, self-reliance, foresightedness, innovativeness, risk taking, self-reflection, discipline, self-confidence, honesty, patience, intelligence.

\section{Study Methodological Procedures:}

\section{1- Study Type:}

The study in hand adopts descriptive and analytical approaches that aim to determine the characteristics of a particular phenomenon and highlight the factors affecting or resulting from it. Within the framework of this study, identifying the entrepreneurial skills of university youth groups is closely examined. 


\section{2- Methodology:}

The study applied the social survey methodology using a general enumeration of university youth groups enrolled in the Entrepreneurship Center and the Business Incubator Center at Assiut University.

\section{3- Study Tools:}

In pursuit of data collection, the researcher used a basic tool - a questionnaire form to determine the entrepreneurial skills of university youth groups. The questionnaire was applied to university youth groups enrolled in the Innovation and Entrepreneurship Centre, Assiut University. Notably, it was built according to the following steps:

\section{1- Collecting and drafting the questionnaire questions:}

This was performed by means of,

- Surveying literature and the conceptual framework on entrepreneurial skills.

- Surveying Arab and foreign research related to the entrepreneurial skills of university youth and how to utilize tools such as questionnaires and scales for the benefit of the study tool.

2- Governance:

A) A group of (11) reviewers, engaging in all social work settings in general and group work in particular, assessed the questionnaire.

B) The researcher amended the questionnaire form according to the reviewers' recommendations regarding omission, amendment or addition of the questions, in pursuit of face validity.

C) Later, the researcher calculated the percentage of the inter-rater agreement on the questionnaire questions. Worth considering, phrases with an agreement degree less than $80 \%$ were excluded.

As a result, the questionnaire meant for university youth consists of (5) axes, each of which has an inventory of indicators. Proportionally, the form was eventually printed to be field-applied online.

\section{3- Study Fields:}

A) Human Field:

A population of (207) male/female university youth enrolled in the Entrepreneurship Center, Assiut University were comprehensively enumerated.

B) Place Field:

Entrepreneurship Center and Business Incubator Center, Assiut University.

C) Time Field:

Field data collection lasted from 6-12-2021 to 4-1-2021.

Results: 010

Table (1): Description of the study sample characteristics:

\begin{tabular}{|c|c|c|c|c|}
\hline \multirow{2}{*}{ No } & Variable & Category & Frequency & Percentage \\
\hline \multirow{3}{*}{1} & \multirow{3}{*}{ Age } & $18-20$ & 73 & $\% 35.27$ \\
\cline { 3 - 5 } & & $21-23$ & 115 & $\% 55.56$ \\
\cline { 3 - 5 } & & $24-$ more & 19 & $\% 9.17$ \\
\hline \multicolumn{2}{|c}{ Total } & $\mathbf{2 0 7}$ & $\% 100$ \\
\hline
\end{tabular}




\begin{tabular}{|c|c|c|c|c|}
\hline \multicolumn{3}{|c|}{ Mean } & \multicolumn{2}{|c|}{21.05} \\
\hline \multicolumn{3}{|c|}{ Standard Deviation } & \multicolumn{2}{|c|}{1.93} \\
\hline \multirow{2}{*}{2} & \multirow{2}{*}{ Gender } & Male & 156 & $\% 75.36$ \\
\hline & & Female & 51 & $\% 24.64$ \\
\hline \multicolumn{3}{|c|}{ Total } & 207 & $\% 100$ \\
\hline \multirow{2}{*}{3} & \multirow{2}{*}{ Religion } & Muslim & 163 & $\% 78.74$ \\
\hline & & Christian & 44 & $\% 21.26$ \\
\hline \multicolumn{3}{|c|}{ Total } & 207 & $\% 100$ \\
\hline \multirow{9}{*}{4} & \multirow{9}{*}{ Faculty } & Medicine & 25 & $\% 12.08$ \\
\hline & & Veterinary Medicine & 29 & $\% 14.01$ \\
\hline & & Pharmacy & 22 & $\% 10.63$ \\
\hline & & Engineering & 37 & $\% 17.87$ \\
\hline & & $\begin{array}{c}\text { Computing \& Information } \\
\text { Science }\end{array}$ & 17 & $\% 8.21$ \\
\hline & & Agriculture & 11 & $\% 5.31$ \\
\hline & & Arts & 23 & $\% 11.11$ \\
\hline & & Social Work & 31 & $\% 14.98$ \\
\hline & & Physical Education & 12 & $\% 5.80$ \\
\hline \multicolumn{3}{|c|}{ Total } & 207 & $\% 100$ \\
\hline
\end{tabular}

\section{Extrapolating the figures above, which clarifies the characteristics of the study sample, the following can be inferred:}

Based on table (1), it is shown that the age variable mean is $M=(21.05)$ whereas the standard deviation is $\sigma=(1.93)$. University youth from 21-23 years are represented by $(55.56 \%)$, while those of ages between 18-20 years constitute (35.27\%). Conversely, the percentage of university youth between 24 years and more amounts (19.7\%). Noticeably, it is evident that most of the study sample are males by $(75.36 \%)$, while females constitute $(24.64 \%)$. With regard to religion, Muslims and Christians are represented by (78.74\%) and (21.26\%) respectively.

Concerning faculty variable, the same table shows the representation percentage of each faculty students in the study sample as follows: Engineering (17.87\%), Social Work (14.98\%), Veterinary Medicine (14.01\%), Medicine (12.08\%), Arts (11.11\%), Pharmacy (10.63\%), Computing \& Information Science (8.21\%), Physical Education (5.80\%) and Agriculture (5.31\%).

These results are consistent with Philip's study (2019), in which he indicated that there is no statistically significant correlation between the type of faculty, whether practical or theoretical and the setting of entrepreneurship. Rather, his study showed that a wide range of university youth taking up diverse disciplines had interest in entrepreneurship projects.

Table (2): The concept of entrepreneurial skills for university youth groups:

\begin{tabular}{|c|l|c|c|}
\hline No & \multicolumn{1}{|c|}{ Variable } & Frequency & Percentage \\
\hline $\mathbf{1}$ & The ability to utilize young people's latent capacities. & 56 & $\% 27.05$ \\
\hline $\mathbf{2}$ & The ability to participate in positive community activities. & 46 & $\% 22.22$ \\
\hline $\mathbf{3}$ & The ability to study potential risks and how to respond to them. & 99 & $\% 47.83$ \\
\hline $\mathbf{4}$ & The ability to perform positive, cooperative or team work. & 54 & $\% 26.09$ \\
\hline $\mathbf{5}$ & The ability to set future goals that accomplish project success. & 87 & $\% 42.03$ \\
\hline
\end{tabular}




\begin{tabular}{|c|l|c|c|}
\hline $\mathbf{6}$ & The ability to compete and innovate concerning the project's marketing ideas. & 133 & $\mathbf{0} 64.25$ \\
\hline $\mathbf{7}$ & The ability to make appropriate decisions commensurate with projects with positive objectives. & 102 & $\% \mathbf{4 9 . 2 8}$ \\
\hline $\mathbf{8}$ & The ability to manage projects, take risks and make profits. & $\mathbf{8 7}$ & $\% \mathbf{0 4 2 . 0 3}$ \\
\hline
\end{tabular}

Based on the data above, it becomes clear to what extent university youth groups are aware of entrepreneurial skills. This is can be seen in terms of representation percentage of each skill: the ability to compete and innovate concerning the project's marketing ideas $(64.25 \%)$, the ability to make appropriate decisions commensurate with projects with positive objectives (49.28\%), the ability to study potential risks and how to respond to them (47.83\%), the ability to set future goals that accomplish project success (42.03\%), the ability to manage projects, take risks and make profits $(42.03 \%)$, the ability to utilize young people's latent capacities $(27.05 \%)$, the ability to perform positive, cooperative or team work $(26.09 \%)$, and the ability to participate in positive community activities $(22.22 \%)$,

Accordingly, the distinction in percentages of university youth groups' perception of the concept of entrepreneurial skills is evident. This may be attributed to their lack of knowledge related to entrepreneurship .

Jefferson (2018) stressed the significance of entrepreneurship awareness and providing entrepreneurs with the adequate experience that helps them manage their projects under the supervision of entrepreneurship centers. This also includes supplying entrepreneurial projects with sufficient funds that help develop them.

Mansour (2019) indicated that there are significant differences in the degree of awareness of the dimensions of both entrepreneurship (proactiveness, innovation, risk and innovation) and intellectual capital (human, structural and interpersonal) among young people.

Table (3): Technical skills for university youth groups:

\begin{tabular}{|c|c|c|c|c|c|c|c|}
\hline No & Technical Skills & Yes & Often & No & Total & Mean & Rank \\
\hline 1 & The ability to contact others verbally & 72 & 35 & 100 & 386 & 1.86 & 6 \\
\hline 2 & The ability to organize programs and projects & 91 & 45 & 71 & 434 & 2.10 & 4 \\
\hline 3 & The ability to help facilitate production process & 57 & 27 & 123 & 348 & 1.68 & 8 \\
\hline 4 & The ability to create internal and external networks & 54 & 33 & 120 & 348 & 1.68 & 8 \\
\hline 5 & The ability to provide various monitoring methods & 33 & 87 & 87 & 360 & 1.74 & 6 \\
\hline 6 & The ability to explore modern ideas and innovations & 98 & 48 & 61 & 451 & 2.18 & 3 \\
\hline 7 & The ability to practice active and mindful listening & 131 & 38 & 38 & 507 & 2.45 & 1 \\
\hline 8 & The ability to interact with others & 121 & 45 & 41 & 494 & 2.39 & 2 \\
\hline 9 & $\begin{array}{l}\text { The ability to apply business management steps on } \\
\text { a specific project }\end{array}$ & 87 & 22 & 98 & 403 & 1.95 & 5 \\
\hline 10 & The ability to write reports of various levels & 43 & 27 & 137 & 320 & 1.55 & 9 \\
\hline & Total & 787 & 407 & 876 & & & \\
\hline & Overall mean & 78.7 & 40.7 & 87.6 & & & 207 \\
\hline & Overall percentage & 38.02 & 19.66 & 42.32 & & & $\% 100$ \\
\hline & Relative strength & \\
\hline
\end{tabular}

\section{Analyzing the data in table (3), it is evident that the entrepreneurial technical skills of university youth groups constitute a relative strength of $(62.23 \%)$, and they are ranked as follows:}

1- The ability to practice active and mindful listening holds a weighted mean of (2.45). This implies the need for a proper understanding of the project, which is attained through positive listening to young people. In this way, they can select their projects efficiently.

2- The ability to interact with others constitutes a weighted mean of (2.39), which may indicate university youth's potential to deal with others in order to identify their actual needs so that projects are designed with high quality. 
3- The abilities to help facilitate production process and create internal and external networks share a weighted mean of (1.68). This indicates that university youth are able to form an integrated system of relationships that would contribute to meeting project goals.

4- The ability to write reports of various levels ranks last with a weighted weight of (1.55), indicates the capacity of young people to learn how to write reports that can determine how big the achievement reached is, besides what the strengths and weaknesses found are.

Table (4): Business management skills for university youth groups:

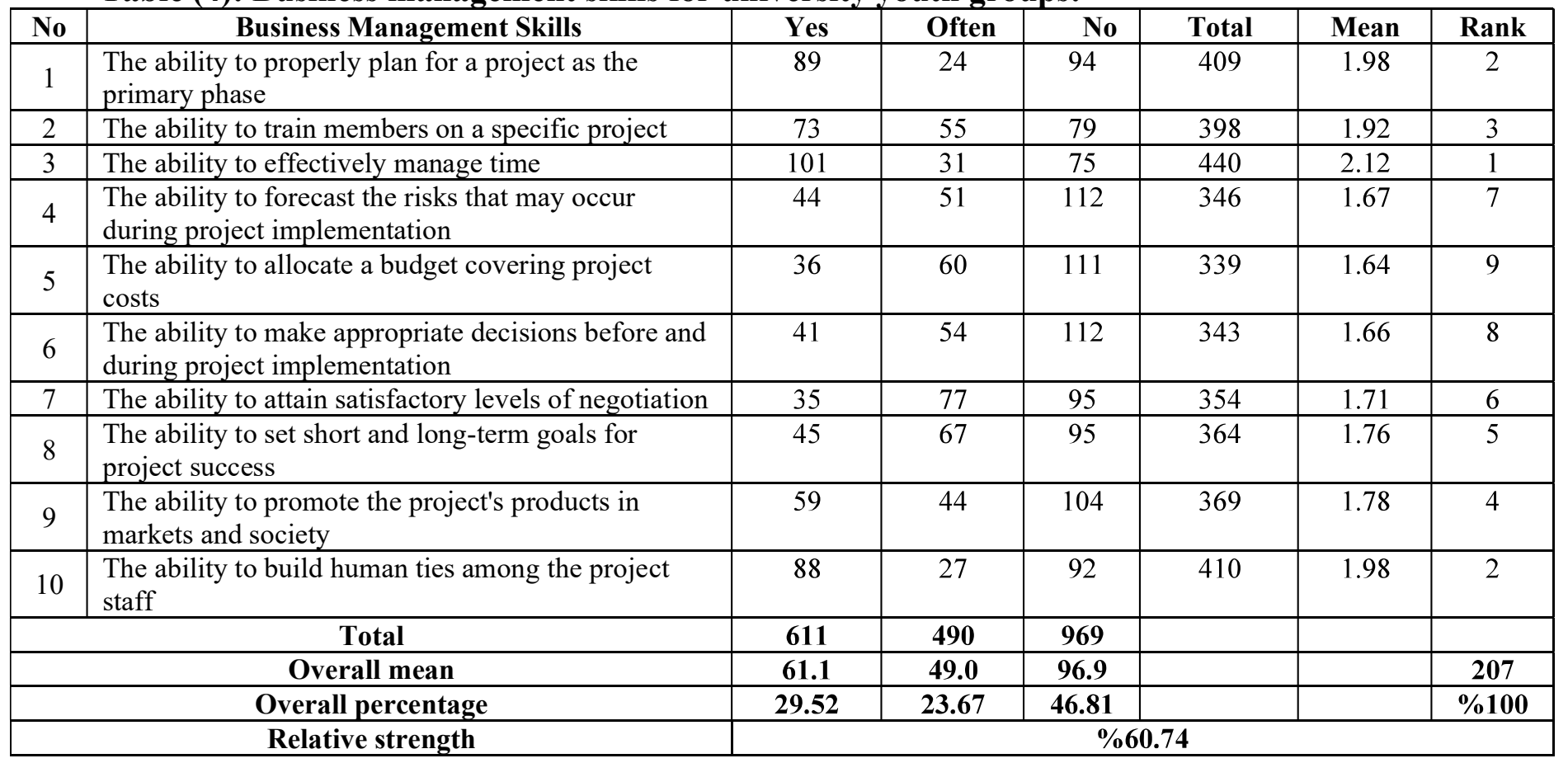

Extrapolating the data in the table above, it is shown that the business management skills of university youth groups constitute a relative strength of $(60.74 \%)$, and they are ranked as follows:

1- The ability to effectively manage time constitutes a weighted mean of (2.12), which may refer to young people's potentials to realize the value of time and how to manage it. In this way, they can divide the project's implementation into stages and prepare its own budgets.

2- The abilities to both properly plan for a project as the primary phase and build human ties among the project staff share a weighted mean of (1.98), which indicates young people's inclination to pursue a sound project planning and create positive relationships that help maintain a project's success.

3- The ability to make appropriate decisions before and during project implementation is represented by a weighted mean of (1.66), which demonstrates their actual tendency to identify decision-making steps and realization that good decisions have a pivotal role in project success.

4- The ability to allocate a budget covering project costs constitutes a weighted mean of (1.64), which may manifest the youth's awareness about the significance of deciding on the budget allocation steps along with the project's actual costs.

These findings are in line with those of the studies conducted by both Naidu (2008) and Rinku (2010) on the necessity of training people in estimating a project budget properly through setting the various goals that ensure the project success. Similarly, Khanka (2014) stressed the need to make sensible decisions that can maintain the success of the project. More, he emphasized, at one hand, determining the risk volume that the project may be exposed to and lead to its 
termination, and on the other hand, considering the perfect marketing of products so that the project can achieve its objectives.

Table (5): Personal skills for university youth groups

\begin{tabular}{|c|c|c|c|c|c|c|c|}
\hline No & Personal Skills & Yes & Often & No & Total & Mean & Rank \\
\hline 1 & $\begin{array}{l}\text { The ability to conduct a feasibility study for the } \\
\text { project before implementation }\end{array}$ & 39 & 69 & 99 & 354 & 1.71 & 8 \\
\hline 2 & $\begin{array}{l}\text { The ability to be self-reliant when taking on } \\
\text { various tasks }\end{array}$ & 66 & 54 & 87 & 393 & 1.90 & 1 \\
\hline 3 & $\begin{array}{l}\text { The ability to apply changes during project } \\
\text { implementation }\end{array}$ & 56 & 42 & 109 & 361 & 1.74 & 7 \\
\hline 4 & The ability to apply different leadership patterns & 49 & 61 & 97 & 366 & 1.77 & 6 \\
\hline 5 & The ability to address potential risks & 65 & 43 & 99 & 380 & 1.84 & 3 \\
\hline 6 & $\begin{array}{l}\text { The ability to communicate with people via several } \\
\text { interviews }\end{array}$ & 55 & 61 & 91 & 378 & 1.83 & 4 \\
\hline 7 & The ability to honestly express society's needs & 44 & 58 & 105 & 353 & 1.71 & 8 \\
\hline 8 & $\begin{array}{l}\text { The ability to incorporate artificial intelligence into } \\
\text { projects }\end{array}$ & 35 & 49 & 123 & 326 & 1.57 & 9 \\
\hline 9 & $\begin{array}{l}\text { The ability to build meaningful social relationships } \\
\text { among those involved in project execution }\end{array}$ & 66 & 45 & 96 & 384 & 1.86 & 2 \\
\hline 10 & $\begin{array}{l}\text { The ability to maintain self-control when handling } \\
\text { consumers }\end{array}$ & 55 & 58 & 94 & 375 & 1.81 & 5 \\
\hline & Total & 530 & 540 & 1000 & & & \\
\hline & Overall mean & 53.0 & 54.0 & 100 & & & 207 \\
\hline & Overall percentage & 25.60 & 26.09 & 48.31 & & & $\% 100$ \\
\hline & Relative strength & \multicolumn{6}{|c|}{$\% 559.10$} \\
\hline
\end{tabular}

Extrapolating the data in table (5), it is shown that the entrepreneurial personal skills of university youth groups constitute a relative strength of $(59.10 \%)$, and they are ranked as follows:

1- The ability to be self-reliant when taking on various tasks comes first with a weighted mean of (1.90). This implies the youth's developing an informational background, which indicates their awareness of the responsibilities laid on them and, in turn, helps in the execution of the project objectives.

2- The ability to build meaningful social relationships among those involved in project execution constitutes a weighted mean of (1.86), which may indicate young people's tendency to engage in positive social relationships that benefit in the implementation of the project steps.

3- The ability to honestly express society's needs ranks third with a weighted mean of (1.71), which demonstrates university youth's inclination to effectively express society needs and their desire to undertake profitable projects.

4- The ability to incorporate artificial intelligence into projects comes last with a weighted mean of (1.57), which may indicate their awareness of the need for applying artificial intelligence, for its role in providing modern technical techniques for entrepreneurial projects.

These results agree with those of Al-Sultan's study (2016), in which he emphasized the significance of providing entrepreneurs with various skills that enable them to chase projects' success. This can be done through designing a range of programs meant to develop their awareness. Similarly, Nicolas (2018), in a relevant study, stressed the need to allocate a set of indicators intended to estimate entrepreneurship development, namely risk-taking, proactiveness and innovation. Moreover, he assumed that the success of entrepreneurial projects can be attained through undertaking creative activities. 
Table (6): Barriers hindering the development of university youth groups 'awareness about entrepreneurial skills:

\begin{tabular}{|c|c|c|c|c|c|c|c|}
\hline No & Personal Skills & Yes & Often & No & Total & Mean & Rank \\
\hline 1 & $\begin{array}{l}\text { Customs and traditions in society do not support } \\
\text { individual initiatives }\end{array}$ & 143 & 35 & 29 & 528 & 2.55 & 7 \\
\hline 2 & $\begin{array}{l}\text { Youths' lack of awareness about entrepreneurship } \\
\text { culture }\end{array}$ & 157 & 44 & 6 & 565 & 2.73 & 4 \\
\hline 3 & Fear of failure in private enterprises & 168 & 12 & 27 & 555 & 2.68 & 5 \\
\hline 4 & $\begin{array}{l}\text { Poor societal awareness of the importance of } \\
\text { entrepreneurship }\end{array}$ & 188 & 9 & 10 & 592 & 2.86 & 2 \\
\hline 5 & Project termination on exposure to early losses & 185 & 6 & 16 & 583 & 2.82 & 3 \\
\hline 6 & $\begin{array}{l}\text { Inefficacy of laws that protect innovations } \\
\text { introduced by entrepreneurial projects }\end{array}$ & 146 & 43 & 18 & 542 & 2.62 & 6 \\
\hline 7 & $\begin{array}{l}\text { Legal and procedural complexity when starting a } \\
\text { private enterprise }\end{array}$ & 119 & 67 & 21 & 512 & 2.47 & 8 \\
\hline 8 & $\begin{array}{l}\text { Insufficient entrepreneurial training programs } \\
\text { meant for youths }\end{array}$ & 191 & 9 & 7 & 598 & 2.89 & 1 \\
\hline 9 & $\begin{array}{l}\text { Enterprise inconsistency with the entrepreneur's } \\
\text { capabilities and skills }\end{array}$ & 57 & 71 & 79 & 392 & 1.89 & 9 \\
\hline 10 & $\begin{array}{l}\text { Insufficiency of funds intended to implement } \\
\text { entrepreneurial projects }\end{array}$ & 121 & 62 & 24 & 511 & 2.47 & 8 \\
\hline & Total & 1475 & 358 & 237 & & & \\
\hline & Overall mean & 147.5 & 35.8 & 23.7 & & & 207 \\
\hline & Overall percentage & 71.27 & 17.29 & 11.44 & & & $\% 100$ \\
\hline & Relative strength & \multicolumn{6}{|c|}{$\% 86.60$} \\
\hline
\end{tabular}

Extrapolating these figures, it is obvious that the obstacles hindering the development of university youth groups' awareness about entrepreneurial skills constitutes a relative strength of $(86.60 \%)$, and they are ranked as follows:

1- Insufficient entrepreneurial training programs meant for youths comes first with a weighted mean of (2.89), which may be attributed to lacking interest in entrepreneurship and overlooking the positive role it can play in limiting unemployment.

2- Poor societal awareness of the importance of entrepreneurship constitutes a weighted mean of (2.86), which may indicate the absence of educational plans that address societal awareness among youth about entrepreneurship.

3- Legal and procedural complexity when starting a private enterprise and insufficiency of funds intended to implement entrepreneurial projects share a weighted mean of (2.47). This may lead university youth to be reluctant to entrepreneurial projects, which aggravates problems.

4- Enterprise inconsistency with the entrepreneur's capabilities and skills comes last with a weighted mean of (1.89). This may imply the degree of entrepreneurs' awareness about selecting activities that are commensurate with their mindsets and capabilities, which would have a positive impact on them.

Relatedly, these results are in accordance with the studies of of Abdullah (2014), Jordan (2016), and Wales (2019), in which they both emphasized the actual role of entrepreneurship and demonstrated the barriers confronting it, including lack of funding, rigidity of legislation and other political hindrances.

\section{General Results of Study:}

The Research reached a set of general results as follows:

A) Characteristics of the research population:

1 - $(55.56 \%)$ of the study sample constitute university students of ages between 21-23 years, while $(19.7 \%)$ are between 24 -more years. 
2- The vast majority are males (75.36\%), while females constitute $(24.64 \%)$.

3- (78.74\%) of the sample are Muslims, while (21.26\%) are Christians.

4- Representation percentage of each faculty students in the study sample can be traced as follows: Engineering (17.87\%), Social Work (14.98\%), Veterinary Medicine (14.01\%), Medicine (12.08\%), Arts (11.11\%), Pharmacy (10.63\%), Computing \& Information Science (8.21\%), Physical Education (5.80\%) and Agriculture (5.31\%).

B) Results related to the concept of entrepreneurial skills for university youth groups:

According to the sample's perspectives, the ability to compete and innovate concerning the project's marketing ideas is seen as the most needed skill by $(64.25 \%)$, while the ability to participate in positive community activities comes last by $(22.22 \%)$.

\section{C) Results related to key technical entrepreneurial skills for university youth groups:}

It was found out that the ability to practice active and mindful listening ranked first with a weighted mean of (2.45), while the ability to write reports of various levels is last with a weighted mean of (1.55).

\section{D) Results related to business management skills for university youth groups:}

The ability to effectively manage time comes first with a weighted mean of (2.12), whereas the ability to allocate a budget covering project costs ranks last with a weighted mean of (1.64).

\section{E) Results related to key personal entrepreneurial skills for university youth groups:}

The ability to be self-reliant when taking on various tasks comes first with a weighted mean of (2.89), whereas the ability to incorporate artificial intelligence into projects comes last with a weighted mean of (1.57).

F) Results related to the barriers hindering the development of university youth groups 'awareness about entrepreneurial skills

Insufficient entrepreneurial training programs meant for youths comes first with a weighted mean of (2.89), whereas enterprise inconsistency with the entrepreneur's capabilities and skills comes last with a weighted mean of (1.89).

A proposed program based on the perspective of group work to promote university youth groups' awareness of entrepreneurial skills:

The researcher designed the proposed program in terms of a set of bases, which can be presented as follows:

\section{First: Program Concept:}

It is a set of activities that university youth groups undertake with the aim of promoting their entrepreneurial skills. In pursuit of this, they practice various activities and programs that are consistent with their tendencies and abilities, and aim at boosting their capacities to design projects corresponding to their actual energies, through the mentoring of a social worker.

\section{Second: Program Basis:}

1- Literature whose results emphasized the need for of developing entrepreneurial skills for university youth groups.

2- Conceptual framework of the social work profession, and in particular group work, with all their implications (technical guidelines).

3- Results of the study in hand.

4- The researcher's observations and interviews with both specialists engaging in the entrepreneurship setting and the faculty of Group Work Department. 
5- The study's principal objective that the researcher attempted to achieve: promoting entrepreneurial skills for university youth groups.

\section{Third: Program Objectives:}

The program is meant to meet a general goal: promoting entrepreneurial skills for university youth groups.

\section{Fourth: Program Considerations:}

Taking into account the program's foundations and objectives (general and subsidiary), the researcher included the following considerations:

1- The clarity of the program's goal for university youth participants.

2- The program being attainable and in line with the nature of enterprises that youth undertake on graduation and the events that society is going through.

3- Considering flexibility and consistency when designing the program; i.e., it suits their capabilities.

4- Taking into account that the program provides university youth trainees with experience that could contribute to enhancing youth's intellectual and skill aspects with regard to entrepreneurship.

5- Attaining accuracy when selecting the scientific tools and methods to be applied.

Fifth: Program Systems:

- Member System: It comprises university youth group who enrolled in the Entrepreneurship Center or Business Incubator Center.

- Objective System: It is to provide an opportunity for every young person to effectively participate in the program contents so that they can foster their entrepreneurial skills.

- Performance System: It includes the entrepreneurs and experts who collaborate in pursuit of the program success.

- Change-maker System: This involves directing the collective interactions of university youth groups and influencing the changes they experience to achieve the program objectives.

\section{Sixth: Program Theoretical Premises:}

1- Systems theory.

2- Small group theory.

3- Entrepreneurship theory.

\section{Seventh: Program Required Skills:}

1- Interview management

2- Group discussion.

3- Recording.

4- Observation.

5- Applying reality in the present time.

6- Group participation.

7- Perfect utilization of society's potentials and resources.

8- Evaluation 


\section{Eighth: Program Applied Strategies:}

- Knowledge Presentation: This strategy is used to present all knowledge on entrepreneurship: dimensions, aspects, significance, multiple entrepreneurial skills, and the implications of not developing them.

- Group Interaction: In this strategy, university youth are divided into pro/anti groups in which the discussion is conducted around a specific topic until it ends up with outlining and reinforcing positive ideas and views, and discarding ones that discourage entrepreneurial enterprises.

- Persuasion: In this strategy, university youth showcase their diverse attitudes towards innovative ideas and projects so that they can be stimulated to adopt positive ones.

- Self-learning: Here, university youth are assisted to alone perform and assess some activities to outline the strengths and weaknesses in their actual performance of their roles when thinking about taking on entrepreneurial enterprises.

- Behavior Change: Applying this, university youth groups are encouraged to change and modify their behaviors concerning addressing risks that may occur as a result of certain circumstances or lack of experience, while explaining why it is crucial to overcome them.

- Group Interaction: In this strategy, constructive interactions are directed among university youth while practicing the program's activities in order to accomplish group cohesion and growth.

- Group Experience Reinforcement: Here, youth's positive behaviors and trends and individual, group and societal responsibility are boosted. This also involves displaying successful past experiences of entrepreneurs.

- Problem-Solving: In this strategy, the problems that the youth were exposed to during the implementation of the various activities included in the program are discussed to be feasibly solved.

\section{Ninth: Program Techniques:}

- Group Discussion: This technique is applied in all stages of the proposed program in order to provide university youth groups with mass knowledge on entrepreneurial skills and their role in the success of any project. The group discussion is managed in terms of a set of techniques, including intellectual stimulation, idea exchange groups, and knowledge refinement using perspective analysis.

- Role-Play: It is applied according to two notions, to ignore any negative ideas that may be adopted by university youth regarding entrepreneurial projects and to support entrepreneurial projects because of their important role in reducing unemployment and providing various job opportunities for youth after graduation. Fulfilling this, scientific methods are used to discriminate between both directions so that denial and acceptance can be apparently accounted for. 
- Lectures and Seminars: In this technique, a set of thoughts and items of knowledge are orally presented on a specific topic by a majored expert addressing a group of audience without providing enough space for participation and discussion. Specifically, key talking points may cover topics like entrepreneurship, entrepreneurship dimensions, entrepreneurship types, entrepreneurial Skills, and others.

- Tenth: Program Professional Roles:

The researcher listed a number of roles that university youth are likely to play in the context of this program: a mentor, an assistant or a facilitator, an expert, a mediator, a stimulator, a professional leader, and a planner.

\section{Eleventh: Program Evaluation Tools:}

- A questionnaire meant for assessing the proposed program is to be applied to university youth engaging with the program. Thus, this helps learn about their attitudes towards it, its benefit for them, the obstacles that interrupt meeting its objectives, and their recommendations to enhance its efficacy.

- A questionnaire meant for assessing the trainees from university youth groups is to be applied to how much they benefited from the program. This can be done through identifying the entrepreneurial knowledge, experience and professional skills that they have acquired. 


\section{Reference}

Abdullah, S., (2014). Policies for promoting Entrepreneurship among Youth in Palestine. Palestinian Economic Policy Research Institute, Palestine.

Abed, El-Majeed (1998). A Group Work-Based Program Meant to Reduce Aggressive Behavior in Children. Master Thesis, Faculty of Social Work, Helwan University.

Ahmed, M., (2002). Social Group work. Hosiptal day, Cairo.

Ahmed, M., (2000). Basic Operations in Group Work. Faculty of Social Work, Helwan University.

Ahmed, N., (2011): Basis of Social Group work. Zahraa El shreq, Cairo.

Ahmed, N., (2012). Practical Operations in Group Work. Zahraa Al-Sharq Publishing Press, Cairo.

Al-Sultan, F., (2016). Entrepreneurship "Challenges and Keys to Success. Research at the Saudi International Conference on Entrepreneurship, Kingdom of Saudi Arabia, Riyadh.

Andre, V., et al (2008). The Relation between Entrepreneurship and Unemployment in Japan. M A, Rotterdam Tinbergen Institute, Japan.

Berzin, S., (2012). Where is Social Work in the Entrepreneurship Movement? Social Work, $57(2)$.

Black, P., (2016). Ethical Issues in Group Work. Oxford University Press, USA.

Chang, J., \& Rieple, A. (2013): Assessing Student's Entrepreneurial Skills development in live Projects. Journal of small Business and Enterprise Development, Vol. 20, No. 1.

Cooney T., OECD (2012). Report for the Workshop on Skills development for SMEs and Entrepreneurship. Entrepreneurship skills for growth-orientated businesses.

Council on Social Work Education (2015). Educational Policy and Accreditation Standards. Alexandria, VA: Author.

Crawshaw, J., \& Budhwar, P., (2021). Human Resource Management: Strategic and International Perspectives. Sage Publication, USA.

Davidsson, P., (2008) The Entrepreneurship Research Challenge. Edward Elgar Publishing, USA.

European Commission (2013), Entrepreneurship 2020 action plan. Reigniting the entrepreneurial spirit in Europe report based on the Euro barometer Survey on Entrepreneurship

Fahmy, M., (2002). Group Work between Theory and Practice. Part II, Modern University Office, Alexandria.

Furman, R., \& Bender, K., (2015). An Experiential Approach to Group Work. Oxford University Press, USA.

Garvin, Ch., \& Galinsky, M., (2017). Handbook of Social Work with Groups. 3ed, Guilford Publication, USA.

GEM, (2016). Global Entrepreneurship Monitor Executive Report. GEM, London

Germane, D., (2016). Entrepreneurship in Society. The Free Press., New York. 
Gordian, E., (2020): Human Development. Akansha Publishers, New Delhi.

Grant,., - John, Mc., (2013). Consciousness and Intentionality. John Benjamin Publishing Co., Amsterdam, Netherlands.

Healy, L., \& Thomas, R., (2020). International Social Work: Professional Action in an Interdependent World. Oxford University Press.

Hessels, J., \& Grilo, I., (2011). Entrepreneurial exit and Entrepreneurial Engagement. Journal of Evolutionary Economics, 21(3).

Jayeoba, F., (2012). Locus of Control, Gender and Entrepreneurial Ability. British Journal of Arts and Social Sciences, 11(1).

Jefferson, F., (2018). Entrepreneurship Education and Training Programs. journal of Higher Education Theory and Practice, 32(3).

Jody, F.,(2004). Program Evaluation. Pearson Education, USA.

Jordan, M., (2016). Social Entrepreneurship Research. Educational and Psychological Measurement, 3(12).

Khanka, S.,(2014). Entrepreneurship and Small Business Management. 4th edition, New Delhi: Sultan Chand \& Sons.

Lackéus, M., (2015). Entrepreneurship in Education-What, Why, When, How. Trento: OECDLEED.

Lindsay, T., \& Orton, S., (2016). Group work Practice in Social Work. Learning Matters, USA.

Madkour, I.,(1975): The Social Science Thesaurus, The General Egyptian Book Authority, Cairo.

Mansour, Amr (2019). Entrepreneurship as a variable in the development of Intellectual Capital among Young People. Published Research, Egyptian Society of Social Workers, 62 (6).

Michael, M., \& Terry, N., (2001). Entrepreneurial and the need for Management Control: Efficiency vs. Effectiveness. "Second Annual USASBE/SBIDA. Joint National Conference in Orlando. Florida.

Nab'a, Sh., (2011). The Effectiveness of a Mythology on the Entrepreneurial Skill for Agricultural Education Students in Egypt. Master Thesis, Department of Agricultural Extension, Mansoura University.

Naidu, N., (2008). Management and Entrepreneurship. New Delhi: I.K International Publishing House.

NASW (2009). Code of Ethics of the National Association of Social Work. USA.

NASW (2010). Code of Ethics of the National Association of Social Workers. USA.

Nick,Z., \& Leach, L., (2010). Beyond hard outcomes: Soft outcomes and engagement as student success. Teaching in Higher Education 15.

Nicolas, K.,(2018). Measurement and Entrepreneurship in Economic Society. Research Policy.

Nyhan, B.,(1998). Competence Development as a Key Organizational Strategy Experiences of European companies. Industrial and Commercial Training 30.

Onuoha G., (2007) Entrepreneurship. AIST International Journal 10. 
Philip, T. (2019). The Impact of a Mentoring Program on Students' Interests in Entrepreneurial Projects. published research, Journal of Educational and Psychological Studies and Sciences, Faculty of Education, Mansoura University.

Regni, R. (2010). Entrepreneurship: Methods of preparing Students in a classroom Environment through the use of Simulation. The International Journal of Learning, $12(16)$.

Richard, S., (2007) Rebuilding Schumpeter's Theory of Entrepreneurship. Conference on Marshall, Hitotsubashi University, Japan.

Rinku, S.,(2010). Ethics and Values in Business Management. Ane Books India, New Delhi.

Roddic, D., (2007). Exceptional Entrepreneurship .European Innovation Centre. London : Global professional publishing Limited.

Roselina, S., (2009). Soft skills at the Malaysian institutes of Higher Learning. Asia Pacific Education Review 10.

Roy, R \& Niladri D, (2016). Cultivating Evidence-Based Entrepreneurship Education (EBEE): A Review of Synchronization Process behind Entrepreneurial Spirit. DLSU Business \& Economics Review 25.

Sharpley, P., (2012). Exploring Entrepreneurial Skills and Competencies in Farm Tourism. $27,(27)$

Simon, P., (2008). Entre preneur ship .self. Employment and the Labour Market. Oxford Handbook. Of Entrep reneurship. New York: Oxford University press.

Smarten, V., (2018). Essentials of Entrepreneurship in Society. Journal of Management Development, 30(2).

Sultan, Al., (2018). The Role of Entrepreneurship in Encouraging University Youth to Innovate Projects. Journal of Psychological and Social Sciences, Faculty of Education, Damanhour University.

Sowers, K., (2015). Social Work Fields of Practice: Historical Trends, Professional Issues, and future opportunities. Wiley Publication, USA.

Terry, O., (2017). Entrepreneurship in Emerging Economies. Palgrave Macmillan, USA.

Thomas, L., (2017).Social Work and Entrepreneurship Education. Article in Journal of Baccalaureate Social Work, 12(5).

Wales, W., (2019). Business Ethics: A Stakeholder and Issues Entrepreneurship Approach. 4th Edition, Thomson-South Western, Ohio.

William, B., (2009): Encyclopedia of Consciousness. Academic Press, Elsevier Inc., Oxford, UK.

Zastrow, Ch.,(2004). Introduction to Social Work and Social Welfare: Empowering People. 8ed, Brooks/Cole, USA.

Zeng, Z., \& Benson H., (2016). How should Entrepreneurship be taught to Students with diverse Experience? Theoretical, Empirical and Pedagogical Approaches, Emerald Group Publishing Limited, 18(2). 